East African Journal of Science, Technology and Innovation, Vol. 1 (1): 2019, 68-81.

This article is licensed under a Creative Commons license, Attribution 4.0 International (CC BY 4.0)

\title{
Microstructure and Residual Stress Effect on the Flexural Strength of Porcelain Tiles Formulated from Locally Available Materials in Uganda
}

\author{
1,2*OCHEN W., ${ }^{*}$ 'UJANGA F.M., ${ }^{1}$ ORURU B.
}

\author{
${ }^{1}$ Department of Physics, Makerere University, Kampala, Uganda, \\ ${ }^{2}$ Department of Physics, Kyambogo University, Kyambogo, Uganda, \\ *Corresponding author: williams.ochen@gmail.com
}

\begin{abstract}
Quartz is an inexpensive raw material used in the production of porcelain tiles. The presence of quartz prevents pyroplastic deformation during sintering. However, the use of quartz particle size exceeding $32 \mu \mathrm{m}$ has a deleterious effect on the flexural strength of porcelain tiles. Therefore, the aim of this study was to investigate the effect of microstructure and residual stress on the flexural strength of porcelain tiles formulated with different quartz particle sizes, within the range of 45 to $200 \mu \mathrm{m}$. The samples made of kaolin, feldspar and quartz were mixed in the ratio of 5:3:2 respectively, and die pressed at $40 \mathrm{MPa}$. Afterwards, the green body was sintered at $1300{ }^{\circ} \mathrm{C}$ for 2 hours at a rate of $60{ }^{\circ} \mathrm{C} / \mathrm{min}$. The microstructure of the sintered body was characterized by using a scanning electron microscope (SEM) to examine the nature and size of the pores. In addition, the residual stress was evaluated based on Xray diffraction $(X R D)$ method and corroborated with SEM. The flexural strength was determined using three points loading method. The samples formulated with quartz particle size of $45 \mu \mathrm{m}$ exhibited smooth granules, and isolated pores within the range of 3-8 $\mu \mathrm{m}$. But, those with $200 \mu \mathrm{m}$ particles size exhibited rough granules, and interconnected pores between 10-34 $\mu \mathrm{m}$. Initially, there was an increase in the residual stress, but above $90 \mu \mathrm{m}$ particle size, it decreased due to evolution of cracks. Also, an increase in quartz particle size resulted in a decline in flexural strength from $33 \pm 1.7$ to $14 \pm 2 \mathrm{MPa}$. These results show that increasing quartz particle size affected the pore morphology and the residual stresses. Therefore, fine quartz particle milling should be taken into account for further improvement of flexural strength.
\end{abstract}

Keywords: Flexural strength; Microstructure; Porcelain tiles; Quartz; Residual stress

Cite as: William Ochen et al, 2019 Microstructure and Residual Stress

Received: $\quad 29 / 07 / 19$ Effect on the Flexural Strength of Porcelain Tiles Formulated from

Accepted: $\quad 14 / 10 / 19$ Locally Available Materials in Uganda

Published: $\quad$ 25/10/19

East African Journal of Science, Technology and Innovation 1(1): 68-81.

\section{Introduction}

In 2013, the global production of ceramic tiles was estimated at 11.9 million square meters, representing a rise of about $6 \%$ compared to 2012. Similarly, in 2017, the production was estimated at 13.5 million square meters, showing an increase of $12 \%$ compared to 2013. The global consumption of ceramic tiles was about 11.5 million square meters, in 2013, giving a rise of 5\% compared to 2012 (Gültekin et al., 2017). In Africa, 0.7 million square meters of ceramic tiles were produced in 2017, giving an increase of about $43 \%$ compared to 2013. In Uganda, a ceramic tile industry was built in 2017 to supply both the local and regional 
markets. These trends show that the demand for ceramic tiles increases every year.

The body composition of commercial ceramic tiles is about 40-50 wt.\% kaolin clay, 35-50 wt.\% feldspar and 10-20 wt.\% quartz (MartínMárquez et al., 2010). Each material has a unique role during sintering; kaolin clay provides the firing strength, feldspar is a flux material which promotes vitrification and quartz prevents body warping after firing (Njindam et al., 2018). Porcelain tiles are ceramic materials sintered at temperatures of about $1200-1400{ }^{\circ} \mathrm{C}$ using a fast firing rate; in order to reduce energy consumption. Within this temperature range $\left(1200-1400{ }^{\circ} \mathrm{C}\right)$, the formation of strength-providing phases like mullite is enhanced during sintering (Lerdprom et al., 2016; Cavalcante et al., 2004). Porcelain tiles are characterized by low water absorption of less than $0.5 \%$ and high flexural strength of greater than $35 \mathrm{MPa}$, making them suitable for both indoor and outdoor applications.

The flexural strength of porcelain tiles is affected by the presence of quartz. Stathis et al. (2004) reported that an increase in the quartz particle size from $10-30 \mu \mathrm{m}$, proliferates the flexural strength according to the pre-stressing effect. This effect is caused by a miss-match in the thermal and elastic properties of the constituent phases, hence inducing compressive stresses within the glassy (matrix) phase (Mukhopadhyay et al., 2006). On the other hand, quartz particle size exceeding 32 $\mu \mathrm{m}$ is detrimental to the mechanical properties, because of their low sinterabilty, which brings about an increase in the size and the number of pores (Bragança et al., 2006; Souza et al., 2006). Notably, the presence of undissolved quartz particles embedded in a glassy phase of a fired body creates residual stresses. These stresses are caused by the difference in the thermal coefficient of quartz $\left(23 \times 10^{-6} \mathrm{~K}^{-1}\right)$ and the glassy phase $\left(3 \times 10^{-6} \mathrm{~K}^{-1}\right)$, during cooling from the firing temperature to room temperature, hence generating cracks within and around the phases present. Also, the formation of cracks in porcelain materials has been reported by (Ece and Nakagawa, 2002; Kobayashi et al., 1992 and Warshaw, 1967).

Studies have proved that, the magnitude of residual stress is affected by varying the particle sizes of quartz. Carty and Pinto (2008) studied the effect of the quartz particle sizes (10-150 $\mu \mathrm{m})$ on the strength of porcelain bodies. The authors reported an increase in the residual stress and a sudden decline for samples with particle size greater than $87 \mu \mathrm{m}$. The decline (stress relaxation) was attributed to creation of cracks, thus leading to loss of strength. Similar work by De Noni et al. (2009) reported a decline in both the stress and flexural strength with an increase in the quartz particle sizes with 48-162 $\mu \mathrm{m}$. Therefore, this study aims to analyze the effect of pore size and shape, and residual stress on the flexural strength of porcelain tiles formulated with different quartz particle sizes within 45 to $200 \mu \mathrm{m}$, and the raw materials used were sourced from selected deposits in Uganda.

\section{Material and methods}

\section{Raw Materials}

The raw materials: kaolin, feldspar and quartz used to formulate the tile samples were sourced from deposits found in Uganda. Mutaka deposit which is found in Bushenyi District in Western Uganda was the source for kaolin and quartz. This deposit is approximately $340 \mathrm{~km}$ from Kampala city and it is on latitude 0042171N and longitude 0469849E. While Lunya deposit is found in Buikwe District 40 $\mathrm{km}$ from Central Uganda (Kampala) provided feldspar. This deposit is on latitude $0049489 \mathrm{~N}$ and longitude 0491129E. These deposits have been studied by Olupot et al. (2010) for the production of electrical porcelain insulators, and proved suitable.

Quartz and feldspar were dry milled in a laboratory ball mill (Retsch, PM 100, German). A pulverized sample of feldspar was passed through a mesh sieve of $50 \mu \mathrm{m}$. Further, quartz 
particle size was varied using different mesh sizes arranged on a sieve shaker (Retsch, AS 200, German), mean sizes of 45, 90 and $200 \mu \mathrm{m}$ were used for this study, based on work by Bragança et al. (2006) and Kobayashi et al. (1992). The samples formulated with different quartz particle sizes were classified according to Table 1.

Table 1: Classification of tile samples

\begin{tabular}{llll}
\hline $\begin{array}{l}\text { Quartz particle } \\
\text { size }(\mu \mathrm{m})\end{array}$ & 45 & 90 & 200 \\
\hline Classification & Fine & Medium & Coarse \\
\hline Batch label & SQ2 & SQ3 & SQ4 \\
\hline
\end{tabular}

\section{Microstructure Analysis}

The chemical analysis of the raw materials was carried out by Atomic Absorption Spectroscopy (Agilent Instruments, Malaysia). The elements present in kaolin, feldspar and quartz were determined in parts per million (ppm), and the percentage of their oxides was calculated. Flame photometry was used to determine the amount of $\mathrm{Na}, \mathrm{K}, \mathrm{Fe}, \mathrm{Ti}$ and $\mathrm{Ca}$ present in the raw materials, while $\mathrm{Si}$ and $\mathrm{Al}$ were determined by the gravimetric method (Dana et al., 2004). The results are presented in Table 2 . The percentage difference in weight between the unfired samples and after 2 hours of firing at $800{ }^{\circ} \mathrm{C}$ was used to determine the loss on ignition (LOI).

The microstructures of the fired tile samples were analyzed using a scanning electron microscope (CARL ZEISS, Instruments). Sectioned and polished tile samples were used for the investigation. The samples were polished, cleaned and dried. Thereafter, they were dipped in $40 \%$ concentrated hydrochloric acid for $25 \mathrm{~s}$, cleaned, dried and studied using CARL ZEISS instrument. The cleaning procedures given to all specimens before examination included washing in water and alcohol before drying. Further, Energy Dissipative X-ray analysis was used to determine the elemental components in the fired tile samples and this was followed by SEM analysis.

\section{Formulation of Tile Samples}

Sixty grams $(60 \mathrm{~g})$ of the powder material composing; $50 \mathrm{wt} . \%$ kaolin, $30 \mathrm{wt}$ \% feldspar and 20 wt. \% quartz (Martín-Márquez et al., 2010), was die pressed with $10 \mathrm{wt} \%$ moisture content. A compaction pressure of $40 \mathrm{MPa}$ was applied, to form rectangular tiles of size $106 \times 50 \times 7 \mathrm{~mm}^{3}$. The green tile samples were left to dry at room temperature for 72 hours, and afterwards, they were fired in an electric furnace (CARBOLITE, GERO, HTF 1700, German). A firing temperature of $1300^{\circ} \mathrm{C}$ was used at a rate of $60^{\circ} \mathrm{C} / \mathrm{min}$, and a dwell time of 1 hour. When the furnace was switched off, the samples were left to cool naturally. And thereafter, the tile samples were subjected to flexural strength and residual stress tests.

\section{Flexural Strength}

The flexural strength of the tile samples was obtained by calculating the Modulus of Rupture (MOR), which was obtained using three points loading method, whereby, the samples were put on two supports, at a distance $(L)$ of $60 \mathrm{~mm}$ apart. Then, a loading force $(F)$ with a rate of $0.5 \mathrm{mms}^{-1}$ was directed to the centre and its value was recorded immediately the sample breaks. The MOR was calculated using Equation 2.1 (Mahdi, 2018). A total of five tile samples were used to compute the average value and the standard deviation.

$$
M O R=\frac{3 F L}{2 b t^{2}}
$$

where $b$ and $t$ are the breadth and thickness of the tile samples respectively.

\section{Residual Stress Evaluation}

The residual stress in the tile samples was evaluated by a non-destructive method. The experiment was carried out using X'pert PRO PAN analytical X-ray diffractometer, PW $3050 / 60$, with $\mathrm{Ni}$ filtered $\mathrm{K}(\alpha 1+\alpha 2) \mathrm{Cu}$ radiation generated by $40 \mathrm{kV}$ acceleration voltage and 40 $\mathrm{mA}$ anode current. The samples were scanned 
from $10^{\circ}$ to $90^{\circ}$, operating the equipment at $2 \theta$ scan speed of $0.5 \mathrm{~s} / \mathrm{step}$ and a $2 \theta$ step size of $0.001^{0}$. X-rays of wavelength, $\lambda=0.15406 \mathrm{~nm}$ was applied on an unpolished tile, put on the sample stage. However, no tilting of the samples was done for all the measurements. The diffracted rays were collected using X'pert Data collector, the diffraction angles, $2 \theta$, and their intensities were recorded.

Phase identification was done using QUALX2.0 software. The quartz peaks were matched with the Crystallography Open Database (COD). Three quartz peak positions (A, B and C) were considered, corresponding to specific crystallographic $\{\mathrm{h} k \mathrm{k}$ l\} planes. The peak diffraction angles, $2 \theta$, and their d-spacing were obtained automatically using the software. The d-spacing was calculated using Bragg's law (Equation 2.2),

$$
2 d \sin \theta=n \lambda
$$

The XRD method for measuring stress in a material uses the crystal plane as the strain gauge. Normally, a stressed material is noticed by a change in the crystal plane spacing. Therefore, the strain, $\varepsilon$, in and around the quartz particles is calculated as a shift in the dspacing, using Equation 2.3 (De Noni et al., 2008),

$$
\varepsilon=\frac{d_{1}-d_{0}}{d_{0}}
$$

where $d_{0}$ is the $\mathrm{d}$-spacing of a stress-free sample. Powder quartz particles size of $45 \mu \mathrm{m}$ was used as a stress-free sample in this study. And, $d_{1}$ is the d-spacing of a stressed (bulk) tile sample. Once the displacement of a given plane was known, Hooke's law was used to compute the residual stress, $\sigma$ using Equation 2.4 (Mastelaroet al., 1999)

$$
\sigma=E \varepsilon
$$

where, E, is the Young's Modulus of the tile sample. In this work, a value of $65 \mathrm{GPa}$ was used based on a study by Martín-Márquez et al. (2010).

\section{Results and discussion}

\section{Microstructure Analysis}

The results presented in Table 2, shows that kaolin, feldspar and quartz used in this study, were of the quality used in the formulation of porcelain tiles (Bragança et al., 2006).

Table 2: Chemical Composition (\%) of the raw materials

\begin{tabular}{llll}
\hline Oxide & \multicolumn{3}{l}{ Composition of raw materials (\%) } \\
\cline { 2 - 4 } & Kaolin & Feldspar & Quartz \\
\hline $\mathrm{SiO}_{2}$ & 53.41 & 62.82 & 99.59 \\
$\mathrm{Al}_{2} \mathrm{O}_{3}$ & 35.64 & 17.23 & ------ \\
$\mathrm{Fe}_{2} \mathrm{O}_{3}$ & 0.03 & 0.14 & 0.04 \\
$\mathrm{Na}_{2} \mathrm{O}$ & 0.04 & 4.32 & 0.04 \\
$\mathrm{~K}_{2} \mathrm{O}$ & 0.01 & 0.30 & 0.02 \\
$\mathrm{CaO}$ & 0.28 & 1.29 & 0.39 \\
$\mathrm{TiO}$ & 0.02 & 0.20 & 0.05 \\
Others & 0.63 & 17.5 & ----- \\
LOI & 9.96 & 1.49 & 0.39 \\
\hline
\end{tabular}

The chemical composition of quartz shows that, it is composed of pure silica (99.6\%). Also, the percentages of silica and alumina found in kaolin and feldspar were within the range reported elsewhere (Olupot et al., 2010). The fluxing agent, sodium oxide is of a high composition compared with potassium and calcium oxides. However, the sodium oxide had a low amount compared to results reported by other workers, probably due to processing techniques. In this case, feldspar was not cleaned; it was covered by quartz and other soils, hence affecting its purity. The flux oxide plays a significant role towards densification, by forming a molten phase that blocks the pores present in the body. Additionally, they contribute to mullite formation where their presence enhances flexural strength (Iqbal and Lee, 2000; Carty and Senapati, 1998 ). The impurities, iron III oxide and titanium dioxide had a low percentage (Table 2). Further, their presence was not detected in the fired samples, therefore, this explains the whiteness of the fired tile samples (Njindam et al., 2018), seen in Fig.1. The Energy Dissipative X-ray analysis (EDX) was used to determine the elemental composition in the fired tile sample. 


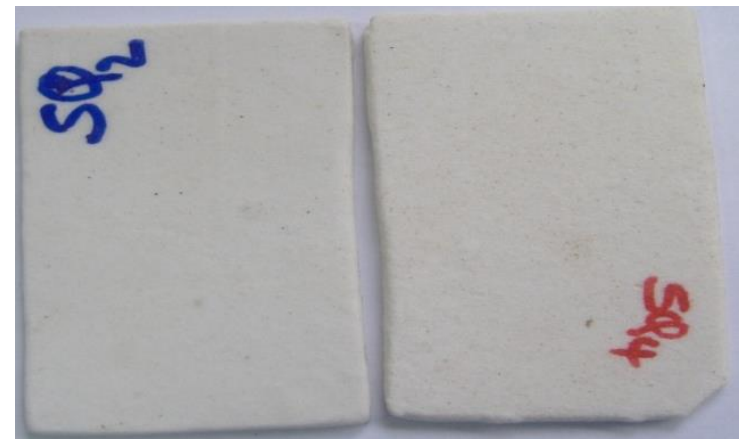

Fig.1: Visual aspects of tile samples fired at $1300^{\circ} \mathrm{C}$

The elemental composition in the fired tile samples (SQ2 and SQ4) was determined using EDX, and the results are illustrated in Table 3. The principle element present in all the fired tile samples is silicon (silica-quartz), represented by the red vertical line (Fig.2 and Fig.3). The percentage of silicon was highest in SQ4 due to larger quartz particle size used (Table.1). Fio. 2 : of coarse particle size leads to large quantities of un dissolved quartz, hence creating more pores and cracks. However, the glassy phase in SQ2 and SQ4 was richer in $\mathrm{Na}$ as illustrated in Table 3.

Table 3: Elemental composition in the fired tile samples

\begin{tabular}{lll}
\hline Element & \multicolumn{2}{l}{ Elemental Composition (\%) } \\
\cline { 2 - 3 } & SQ2 & SQ4 \\
\hline $\mathrm{O}$ & 57.44 & 65.27 \\
$\mathrm{Si}$ & 24.6 & 33.92 \\
$\mathrm{Al}$ & 6.42 & 3.96 \\
$\mathrm{~K}$ & 1.96 & 0.92 \\
$\mathrm{Na}$ & 3.22 & 2.37 \\
$\mathrm{Ca}$ & 0.59 & 0.29
\end{tabular}


dissolve the coarse quartz particles, leading to a "lake" of un-melted particles.

There were pores present in both SQ2 and SQ4 tiles, because of the decomposition of organic matter and the low sinterability of particles such as quartz (Xie et al., 2012). The morphology of these pores was affected by the size of quartz particles in the starting composition. The presence of pores in the material has two key aspects; firstly, they reduce the overall loadbearing area, therefore flexural strength will be dependent on the minimum contact area. Secondly, pores lead to stress concentration, thereby facilitating crack growth hence affecting flexural strength (Boccaccini, 1998).

Spherical, isolated and uniformly distributed pores (Fig. 4c), are advantageous due to crackpore interaction, and usually there is a larger-load bearing area (neck). This type of pores act as "a full-stop" to the growth of cracks induced by external stress (Aduda and Nyongesa, 2003), hence relating to a higher MOR value of $33 \pm 1.7$ MPa exhibited by SQ2 tile samples. Further, these pores were in the range of 3-8 $\mu \mathrm{m}$, and studies have proved that pores in the range of less than $20 \mu \mathrm{m}$ have a positive effect on the flexural strength (Xie et al., 2012). But, SQ4 tile samples exhibited irregular and interconnected pores, within the range of 11-38 $\mu \mathrm{m}$ (Fig. $4 \mathrm{~d}$ ). These abnormal pores are detrimental to the flexural strength of the tiles, because they act as the origin of fracture, and they also facilitate crack propagation. This explains the low MOR value of $14 \pm 2 \mathrm{MPa}$ exhibited by SQ4 tile samples. Therefore, pore morphology due to partial quartz sintering, is among the major factors hindering the flexural strength of tiles.
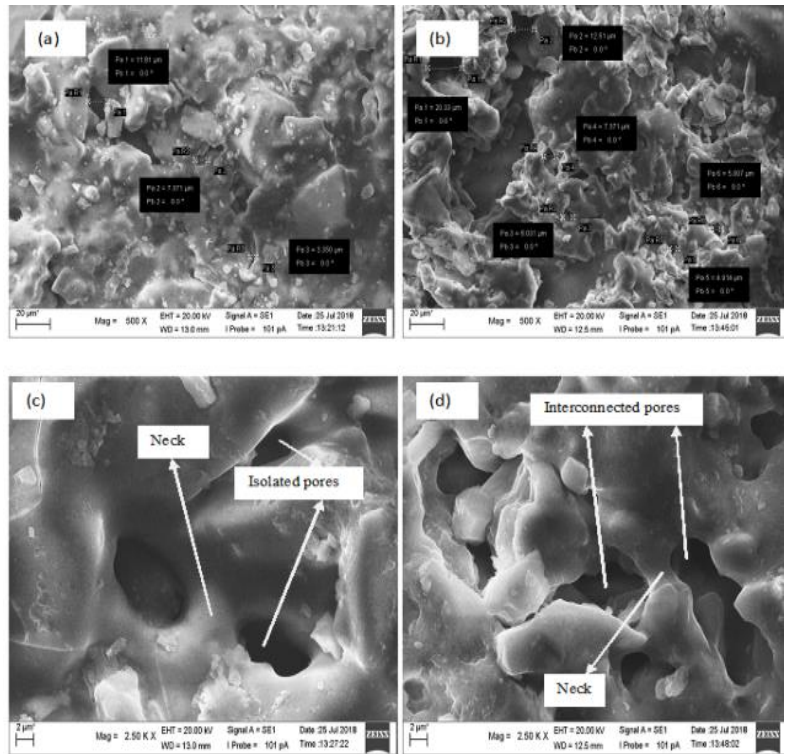

Figure 4: SEM micrographs; (a) and (b) shows smooth and rough granular texture of SQ2 and SQ4 tiles respectively, (c) and (d) represents pore nature, exhibited by SQ2 and SQ4 tiles respectively.

Further analysis of the SEM micrographs for SQ2 and SQ4 samples, divulged cracks in SQ4 tiles (Fig. 5b), yet SQ2 tiles had a dense and crack -free microstructure as seen in Fig. 5a. These cracks were formed as a result of stress relaxation. Studies have proved that a miss-match in the thermal properties of quartz and the glassy phase brings about stresses during cooling. But, the stress level lowers when cracks begin to form (Chmelík et al., 2011). Also, there were infinitesimal mullite sites spotted in only SQ2 tile samples; very likely caused by the low content of the alkali oxides in feldspar (Table 2). The presence of mullite enhances the flexural strength in accordance with the mullite hypothesis.

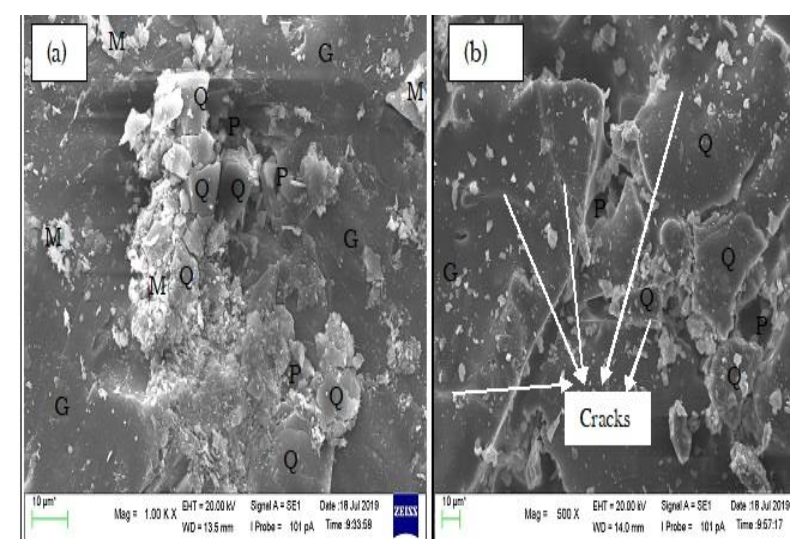


Fig. 5: SEM micrographs showing, Q-quartz, Gglassy phase, M-mullite crystals and cracks for (a) SQ2 and (b) SQ4 tiles.

\section{Residual Stress Measurement}

First, the major crystalline phase presence in the tile samples was identified using QUALX2.0 software. The quartz peaks were recognized by COD card number 00-152-6860 and 00-153-2512 . Notably, the presence of $\mathrm{SiO}_{2}$ (quartz) in the fired samples was also confirmed by the EDX analysis. Likewise, the very software was used to identify

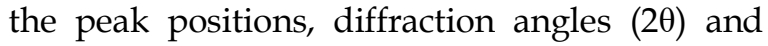
their corresponding $\mathrm{d}$-spacing. Only three peak positions A, B and C (Fig. 6), corresponding to specific quartz crystallographic $\{\mathrm{h} k \mathrm{k}\}$ planes, were used to calculate the strain and residual stress.

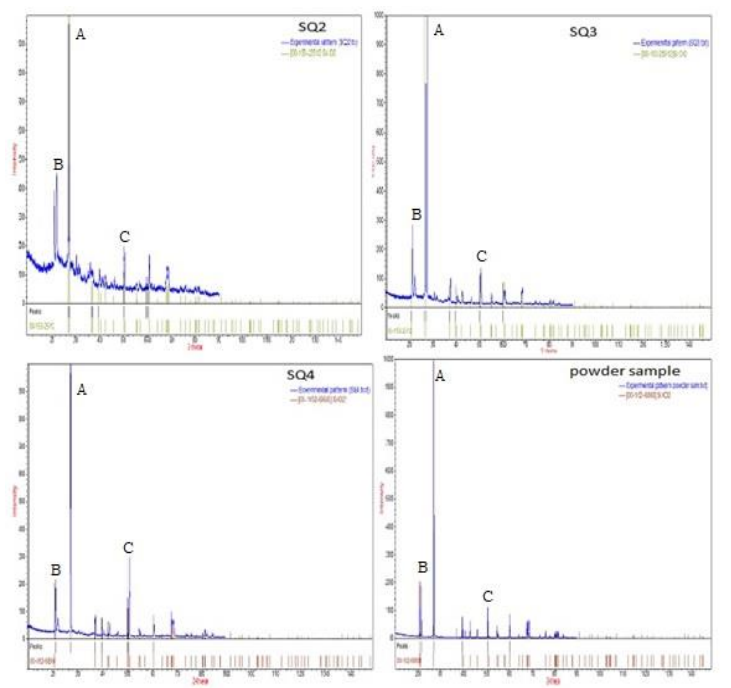

Fig. 6: XRD patterns for SQ2, SQ3, SQ4 and Powder sample. A, B and $\mathrm{C}$ represents the peak position of the quartz $\left(\mathrm{SiO}_{2}\right)$ phase.

Fig. 7 shows the residual stress characteristic and the strain (inset) of the samples with different quartz particle sizes. Both the residual stress and strain exhibited a similar behavior. But, the difference in the maximum values of residual stresses and strains is attributed to quartz anisotropy.

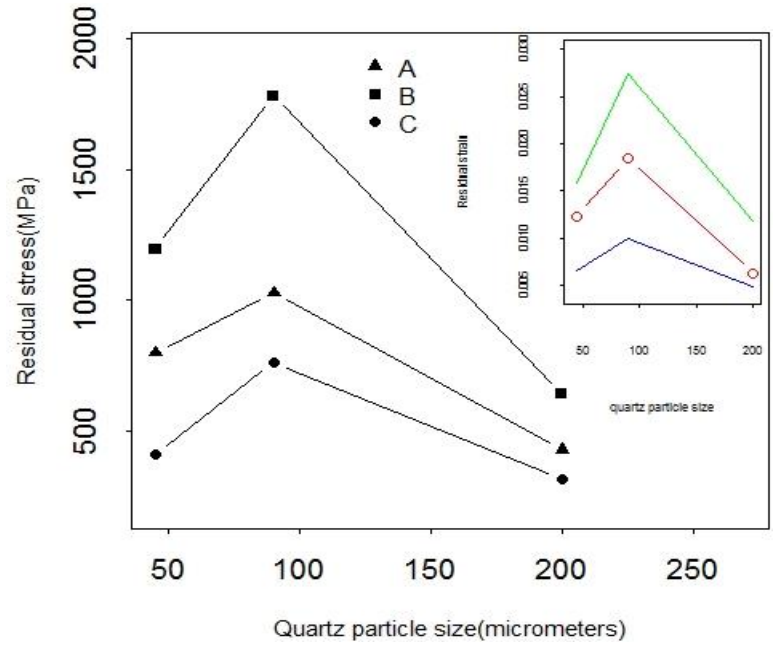

Fig.7: Residual stress and strain (inset) characteristics of the tile samples with different quartz particle sizes.

An increase in the quartz particle size increased the residual stress; the residual stress reached a maximum point, and then decreased with a further increase in the quartz particle size. The highest value of the residual stress was exhibited by SQ3 $(90 \mu \mathrm{m})$ samples. This behavior shows that there is a critical quartz particle size that produces the maximum stress value, and above which the stress declines. A similar study done by Carty and Pinto (2008), noted that quartz particle sizes exceeding $87 \mu \mathrm{m}$ would cause stress relaxation during cooling, thereby setting up cracks, as seen in Fig. 5b. This may explain the observed trend, but in actual sense the phenomenon is complex. On account of the stress relaxation or formation of cracks, the MOR value of $14 \pm 2$ exhibited by SQ4 tile samples was expected. These cracks are aided by the variation in the thermal coefficient between quartz $\left(23 \times 10^{-6} \mathrm{~K}^{-1}\right)$ and the surrounding glassy phase $\left(3 \times 10^{-1} \mathrm{~K}^{-1}\right)$, normally during cooling from 750 to $20{ }^{\circ} \mathrm{C}$ (Mukhopadhyay et al., 2006).

\section{Flexural Strength}

The flexural strength decreased with an increase in the quartz particle size as illustrated in Fig.8. An average value of $33 \mathrm{MPa}$ with a standard deviation of 1.7 MPa was exhibited by SQ2 tile samples. This shows that SQ2 tile samples range within $35 \pm 2$ $\mathrm{MPa}$ required for porcelain floor tiles according to ISO 13006 standards. Also, a mean value of $25 \mathrm{MPa}$ 
with a standard deviation of $1.4 \mathrm{MPa}$ was recorded for SQ3 tile samples, while SQ4 tile samples had a value of $14 \mathrm{MPa}$ with a standard deviation of 2 $\mathrm{MPa}$. These results further show that both SQ3 and SQ4 tile samples were greater than $12 \mathrm{MPa}$, hence recommended for use as wall tiles (Njindam et al., 2018; Njoya et al., 2017).

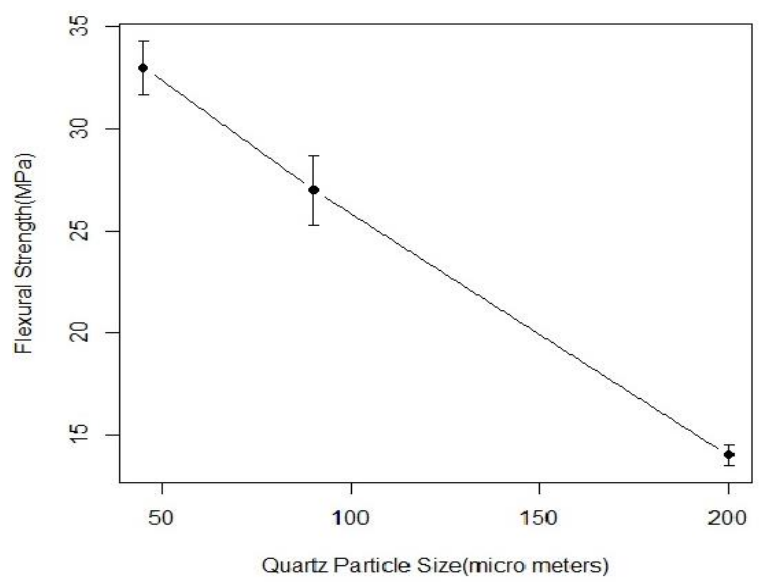

Fig.8: Flexural strength of tile samples with different quartz particle sizes

The decrease in the flexural strength was attributed to pore morphology (Fig. 4c and Fig. $4 \mathrm{~d})$. The isolated pores observed in SQ2 tiles prevent the growth of any crack, for this reason increasing the flexural strength. On the other side, interconnected pores observed in SQ4 tile samples appear to have facilitated the crack propagation, therefore reducing the strength. The low strength exhibited by SQ4 tile samples was also caused by the creation of cracks (Fig. 5b) due to stress relaxation. Further, the infinitesimal mullite crystals seen in Fig. 5a, added to the flexural strength of SQ2 tile samples (Stathis et al., 2004). However, none mullite was observed in SQ4 samples.

Recently, Boussouf et al. (2018), reported that the presence of mullite reduces the formation cracks. Additionally, mullite crystals are known for their strengthening mechanism. The mullite hypothesis suggests that interlocking of needle shaped mullite crystals increases the strength of porcelain tiles. Also, the strength of tiles increases with an increase in the population of these needles.

The development of mullite takes place in stages. First, kaolinite present in kaolin and feldspar dehydrates into metakaolin at about $600{ }^{\circ} \mathrm{C}$, according to equation 2.5

$$
\begin{aligned}
& \mathrm{Al}_{2} \mathrm{O}_{3} \cdot 2 \mathrm{SiO}_{2} \cdot 2 \mathrm{H}_{2} \mathrm{O}(\text { kaolinite }) \\
& \quad \rightarrow \mathrm{Al}_{2} \mathrm{O}_{3} \cdot 2 \mathrm{SiO}_{2}(\text { metakoline })+2 \mathrm{H}_{2} \mathrm{O}
\end{aligned}
$$

Then, the metakaoline is transformed into unstable spinel at $980^{\circ} \mathrm{C}$. Further increase in temperature to greater than $1200{ }^{\circ} \mathrm{C}$ transforms the spinel to mullite according to Equation 2.6 (Njindam et al., 2018),

$$
\begin{aligned}
& \mathrm{Al}_{2} \mathrm{O}_{3} .2 \mathrm{SiO}_{2} \\
& \quad \rightarrow 1 / 3\left(3 \mathrm{Al}_{2} \mathrm{O}_{3} .2 \mathrm{SiO}_{2}\right)(\text { mullite })+4 / 3\left(\mathrm{SiO}_{2}\right)
\end{aligned}
$$

\section{Conclusion}

The aim of this study was to analyze the effect of microstructure and residual stress on the flexural strength of porcelain tiles made from locally sourced materials in Uganda. The tile samples were formulated using different quartz particle sizes within the range of $45-200 \mu \mathrm{m}$. The results revealed that pore morphology of the samples changed as a result of low sinterability of quartz particles. The SQ2 tile samples exhibited a spherical and uniformly distributed pores, yet the SQ4 tiles had irregular and interconnected pores. These types of pores affected the flexural strength of the samples. Whereby, the SQ2 tiles had a value of $33 \pm 1.7 \mathrm{MPa}$, while SQ4 tiles exhibited a value of $14 \pm 2 \mathrm{MPa}$. In addition, SQ3 recorded a value of $25 \pm 1.4 \mathrm{MPa}$. These results proved that SQ2 samples satisfy the requirement of less than $35 \pm 2 \mathrm{MPa}$ for porcelain floor tiles according to ISO 13006 standards. Meanwhile, SQ3 and SQ4 samples satisfy the condition of less than $12 \mathrm{MPa}$ required for wall tiles. On the other hand, there was an initial increase in the residual stress, and the a sharp decline for sample with quartz particle size greater than $90 \mu \mathrm{m}$. The decline was attributed to the formation of cracks, which further reduced the strength. Therefore, fine milled quartz particles, should be used for better improvement of the flexural strength. 


\section{Acknowledgement}

In a special way, I thank the DAAD for the financial support.

\section{References}

Aduda, B. O., \& Nyongesa, F. W. (2003). Role of aspect ratio in elastic modulus-porosity relationship of triaxial porcelain. British Ceramic Transactions, 99(5), 206-211.

Boccaccini, A. R. (1998). Influence of stress concentrations on the mechanical propertyporosity correlation in porous materials. Journal of Materials Science Letters, 17(15), 1273-1275.

Boussouf, L., Zehani, F., Khenioui, Y., \& Boutaoui, N. (2018). Effect of Amount and Size of Quartz on Mechanical and Dielectric Properties of Electrical Porcelain. Transactions of the Indian Ceramic Society, 77(3), 132-137.

Bragança, S. R., Bergmann, C. P., \& Hübner, H. (2006). Effect of quartz particle size on the strength of triaxial porcelain. Journal of the European Ceramic Society, 26(16), 3761-3768.

Cam, W. M., \& Senapati, U. (1998). Porcelain-Raw Materials, Processing, Phase Evolution, and Mechanical Behavior. J. Am Ceram Soc. 81(1),3-20.

Carty, W. M., \& Pinto, B. M. (2008). Effect of Filler Size on the Strength of Porcelain Bodies, Am Ceram. Soc. 6(4),95-105.

Cavalcante, P. M. T., Dondi, M., Ercolani, G., Guarini, G., Melandri, C., Raimondo, M., \& Rocha E Almendra, E. (2004). The influence of microstructure on the performance of white porcelain stoneware. Ceramics International, 30(6), 953-963.

Chmelík, F., Trník, A., Štubňa, I., \& Pešička, J. (2011). Creation of microcracks in porcelain during firing. Journal of the European Ceramic Society, 31(13), 2205-2209.

Dana, K., Das, S., \& Das, S. K. (2004). Effect of substitution of fly ash for quartz in triaxial kaolin-quartz-feldspar system. Journal of the European Ceramic Society, 24(10-11), 31693175 .
De Noni, A., Hotza, D., Soler, V. C., \& Vilches, E. S. (2008). Analysis of the development of microscopic residual stresses on quartz particles in porcelain tile. Journal of the European Ceramic Society, 28(14), 2629-2637.

De Noni, A., Hotza, D., Soler, V. C., \& Vilches, E. S. (2009). Effect of quartz particle size on the mechanical behaviour of porcelain tile subjected to different cooling rates. Journal of the European Ceramic Society, 29(6), 10391046.

Ece, O. I., \& Nakagawa, Z. E. (2002). Bending strength of porcelains. Ceramics International, 28(2), 131-140.

Gültekin, E. E., Topateş, G., \& Kurama, S. (2017). The effects of sintering temperature on phase and pore evolution in porcelain tiles. Ceramics International, 43(14), 11511-11515.

Iqbal, Y., \& Lee, W. E. (2000). Microstructural evolution in triaxial porcelain. Journal of the American Ceramic Society, 83(12), 3121-3127.

Kobayashi, Y., Ohira, O., Ohashi, Y., \& Kato, E. (1992). Effect of Firing Temperature on Bending Strength of Porcelains for Tableware. Journal of the American Ceramic Society, 75(7), 1801-1806.

Lerdprom, W., Chinnam, R.K., Jayaselam, D.D., Lee, W.E. (2016). Porcelain production by direct sintering. Journal of the European Ceramic Society, 36(16), 4319-4325.

Li, O., Mastelaro, V. R., \& Zanotto, E. D. (1999). Anisotropic residual stresses in partially crystallized, 247, 79-86.

Mahdi, O. S. (2018). Study the Influence of Sintering on the Properties of Porcelain Stoneware Tiles, 13(6), 3248-3254.

Martín-Márquez, J., Rincón, J. M., \& Romero, M. (2010). Effect of microstructure on mechanical properties of porcelain stoneware. Journal of the European Ceramic Society, 30(15), 3063-3069.

Mukhopadhyay, T. K., Ghosh, S., Ghatak, S., \& Maiti, H. S. (2006). Effect of pyrophyllite on vitrification and on physical properties of triaxial porcelain. Ceramics International, 32(8), 871-876.

Njindam, O. R., Njoya, D., Mache, J. R., Mouafon, M., Messan, A., \& Njopwouo, D. (2018). 
Effect of glass powder on the technological properties and microstructure of clay mixture for porcelain stoneware tiles manufacture. Construction and Building Materials, 170, 512-519.

Njoya, D., Tadjuidje, F. S., Ndzana, E. J. A., Pountouonchi, A., Tessier-Doyen, N., \& Lecomte-Nana, G. (2017). Effect of flux content and heating rate on the microstructure and technological properties of Mayouom (Western-Cameroon) kaolinite clay based ceramics. Journal of Asian Ceramic Societies, 5(4), 422-426.

Olupot, Peter W., Jonsson, S., \& Byaruhanga, J. K. (2010). Development and characterisation of triaxial electrical porcelains from Ugandan ceramic minerals. Ceramics International, 36(4), 1455-1461.

Souza, G. P., Messer, P. F., \& Lee, W. E. (2006). Effect of varying quartz particle size and firing atmosphere on densification of Brazilian clay-based stoneware. Journal of the American Ceramic Society, 89(6), 1993-2002.

Stathis, G., Ekonomakou, A., Stournaras, C. J., \& Ftikos, C. (2004). Effect of firing conditions, filler grain size and quartz content on bending strength and physical properties of sanitaryware porcelain. Journal of the European Ceramic Society, 24(8), 2357-2366.

Turkmen, O., Kucuk, A., \& Akpinar, S. (2015). Effect of wollastonite addition on sintering of hard porcelain. Ceramics International, 41(4), 5505-5512.

WARSHAW, S. I., \& SEIDER, R. (1967). Comparison of Strength of Triaxial Porcelains Containing Alumina and Silica. Journal of the American Ceramic Society, 50(7), 337-343.

Xie, Y., Meng, Y., Liu, S., Gong, G., Wu, Z., \& Yin, Z. (2012). Fabrication and microstructure investigation of ultra-high-strength porcelain insulator. Journal of the European Ceramic Society, 32, 3043-3049 